\title{
ArcheoSciences
}

Revue d'archéométrie

33 (suppl.) | 2009

Mémoire du sol, espace des hommes

\section{EM-I sensor NEMFIS: method, equipment and case stories of archaeological prospection}

Yuri Manstein and Alexander Manstein

\section{(2) OpenEdition}

1 Journals

\section{Electronic version}

URL: https://journals.openedition.org/archeosciences/1775

DOI: 10.4000/archeosciences. 1775

ISBN: 978-2-7535-1599-4

ISSN: 2104-3728

Publisher

Presses universitaires de Rennes

\section{Printed version}

Date of publication: 30 October 2009

Number of pages: $321-324$

ISBN: 978-2-7535-0943-6

ISSN: $1960-1360$

\section{Electronic reference}

Yuri Manstein and Alexander Manstein, "EM-I sensor NEMFIS: method, equipment and case stories of archaeological prospection", ArcheoSciences [Online], 33 (suppl.) | 2009, Online since 30 October 2011, connection on 21 September 2021. URL: http://journals.openedition.org/archeosciences/1775 ; DOI: https://doi.org/10.4000/archeosciences. 1775 


\title{
EM-I sensor NEMFIS: method, equipment and case stories of archaeological prospection
}

\author{
Yuri Manstein* and Alexander Manstein*
}

Key words: EM-I sensor, 2-D and 3-D visualization.

Sounding with alternating electromagnetic fields, including Frequency Domain Electromagnetic Induction (FD-EMI) sounding methods, have received increasing attention and broad application during the last three decade. A portable electromagnetic sensor (NEMFIS, aka EMS), developed at IPGG (Siberian Branch of the Russian Academy of Sciences), and based on alternating electromagnetic fields, is described in this work. The paper presents a specific application to the near-surface investigation of historical resources.

The device (Fig. 1) consists of the following components: transmitter of harmonic signal with $30-\mathrm{cm}$ diameter coil and two receivers with opposite momentums and spacing between transmitting and receiving coils 1.5 and $2.5 \mathrm{~m}$ inside a radio, transparent, banjo-like body; BlueTooth remote control device and BlueTooth GPS receiver [3]. Data processing software allows building geoelectric maps and/or cross-sections of apparent resistivity or conductivity. Then $2 \mathrm{D}$ and $3 \mathrm{D}$ geoelectric vizualisation can be built using any commercial $2 \mathrm{D}$ and $3 \mathrm{D}$ data viewer. The apparent resistivity measured by NEMFIS is well adapted (in 2006) to the range of resistivity from 1 to $200 \mathrm{Ohm} \cdot \mathrm{m}$. In resistive media, measurements are still informative but only from a qualitative point of view. The sounding, i.e. changing of signal penetration depth, is obtained by frequency change. The device is able to function at any set of 14 predefined frequencies. Operation time at one station depends on the number of frequencies: $0.2 \mathrm{sec}$ at one frequency $-2.5 \mathrm{sec}$ at 14 frequencies.

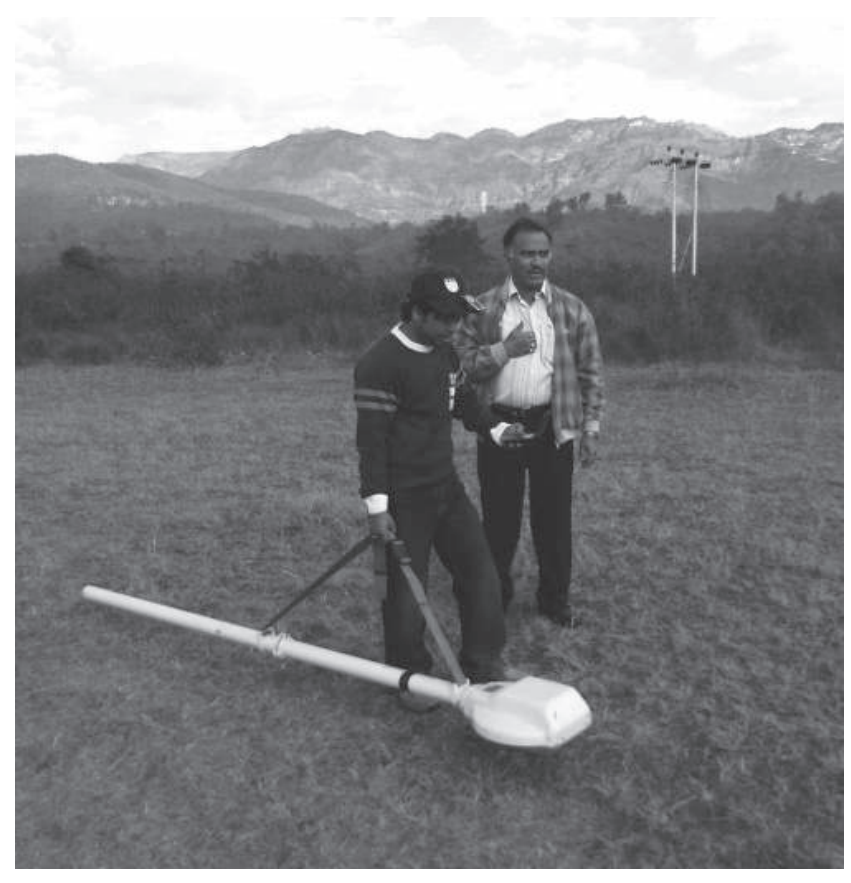

Figure 1: NEMFIS in action.

The device parameters are:

- Type : Frequency Domain Electromagnetic Induction Sounding

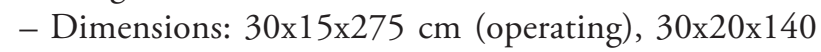
$\mathrm{cm}$ (transportation)

\footnotetext{
* Trofimuk Institute of Petroleum Geology and Geophysics, SB RAS, Novosibirsk, Russia (mansteinya@ipgg.nsc.ru).
} 
- Frequency range: $2.5-250 \mathrm{kHz}$

- Number of operating frequencies: up to 14

- Transmitter power: $600 \mathrm{~W}$

- Battery operation time: 10 hours

- Memory: PDA flash memory

- Receiver sensitivity: $1 \mu \mathrm{V}$

- Noise floor: $50 \mathrm{nV}$;

- Weight: $8 \mathrm{~kg}$

Experiments were carried out using frequency-domain EMI soundings with application of NEMFIS for archaeological applications and assessment of the capability of this technique.

The Scythian settlement of Cicah is located in the Novosibirsk area. The general magnetic map of the settlement was made by Dr. Fassbinder and Dr. Becker [1] and was followed by studies with NEMFIS of particular spots. Site 15 was explored using a 1 by $1 \mathrm{~m}$ grid prior to excavation to acquire more detailed information. The $40 \mathrm{kHz}$

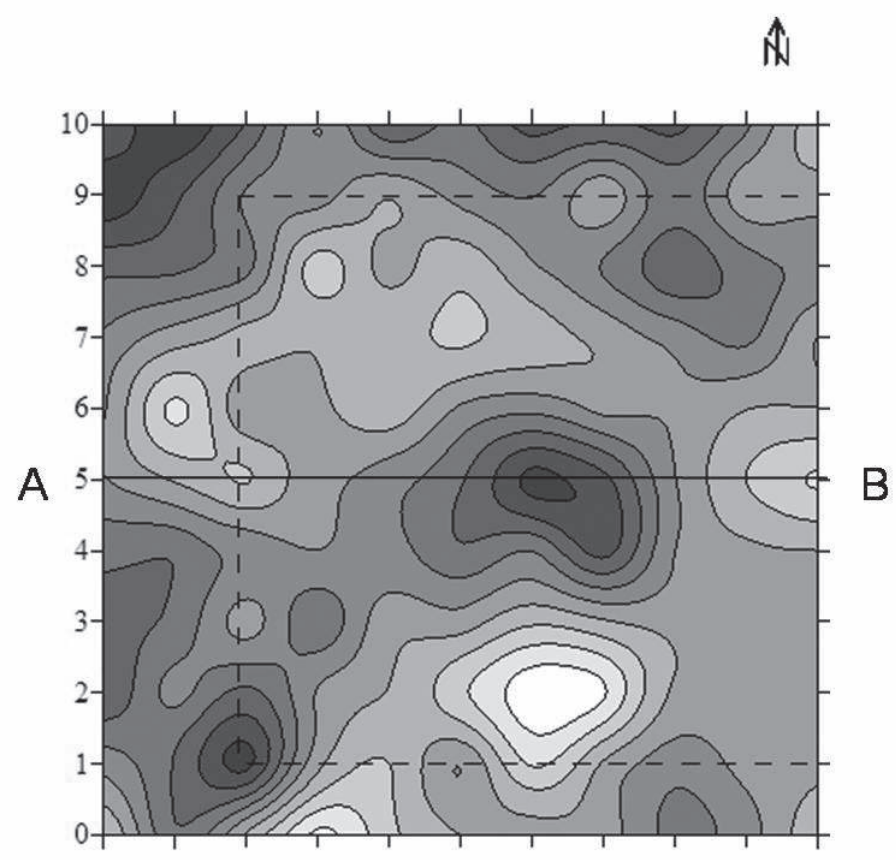

A

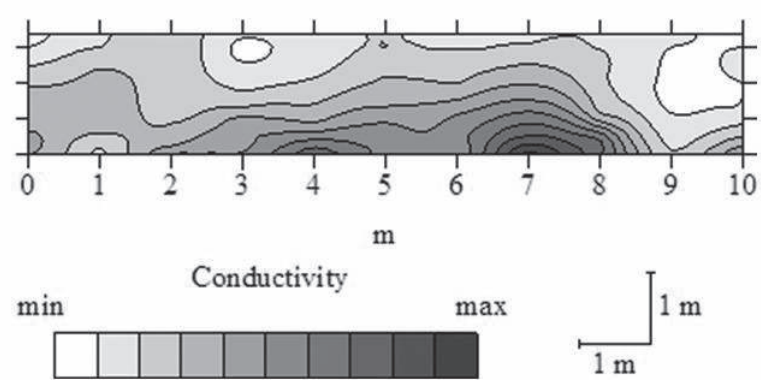

conductivity distribution shows the most interesting results. To obtain vertical distribution, a cross-section was built, using the 111, 64, 40 and $27 \mathrm{kHz}$ frequencies. Total suggested depth of the cross-section is $1 \mathrm{~m}$. There is a good correlation between NEMFIS signal distribution and the site inner structure (Fig. 2). The dotted contour on the map corresponds to the excavated area. The central high conductivity anomaly was explored and interpreted as a result as an ancient toilet: the central anomaly corresponded to a filling of coprolites (elements 3 and 4 of the geological sketch), covered with ash enriched loamy sands used as a sorbent (element 2 of the geological sketch). The ash is the reason for the shallow-depth high-conductivity anomaly. Excavation results are shown as geological sketch along line $\mathrm{CD}$ and a structural map. Fig. 2 presents the excavation viewed from the north.

Case studies from the South Altay Mountains and from Siberia are described in this context. The burial mounds of
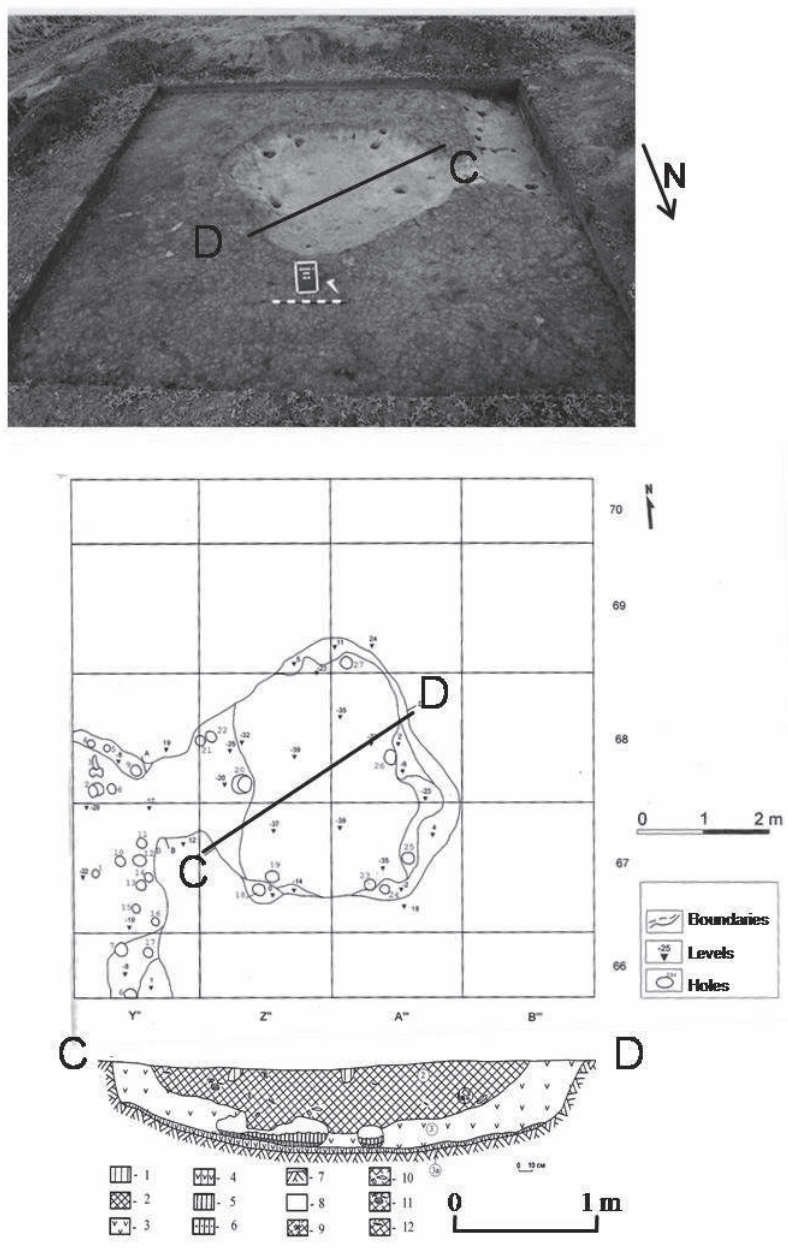

Figure 2. Site 15 of the Cicah settlement: NEMFIS map and cross-section (left) and excavation results (right). 


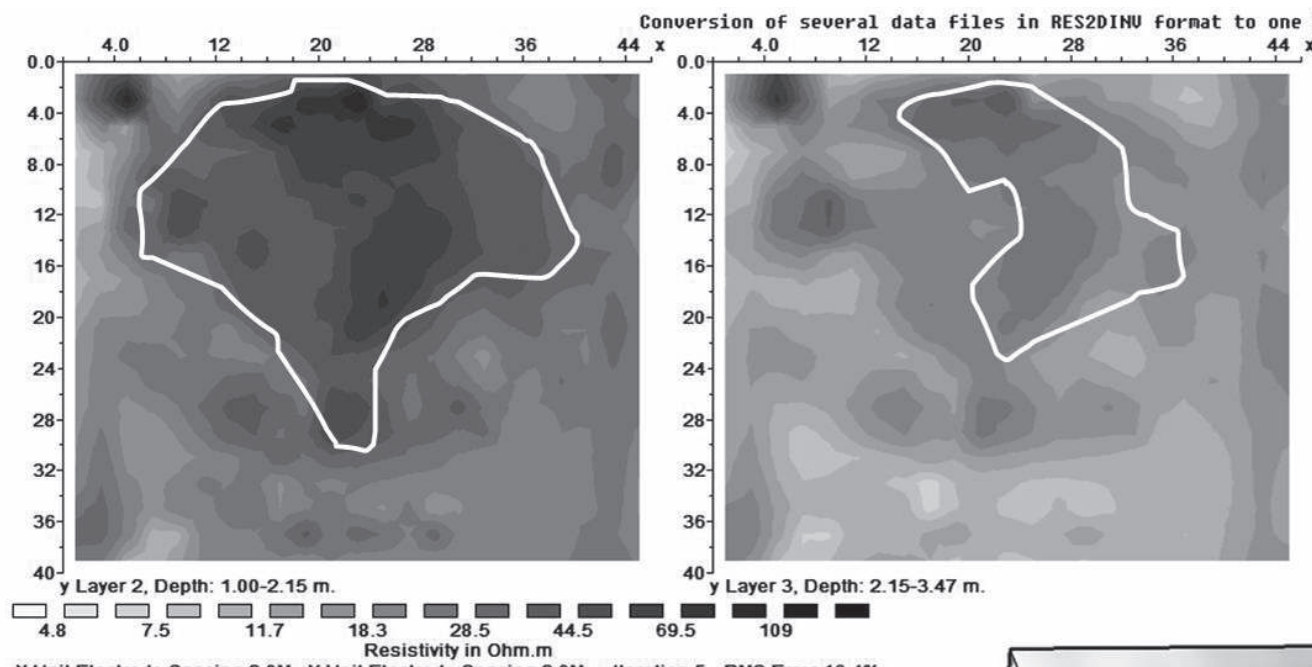

$\mathrm{X}$ Unit Electrode Spacing 2.0M. Y Unit Electrode Spacing 2.0M. Iteration 5 - RMS Error 16.4\%
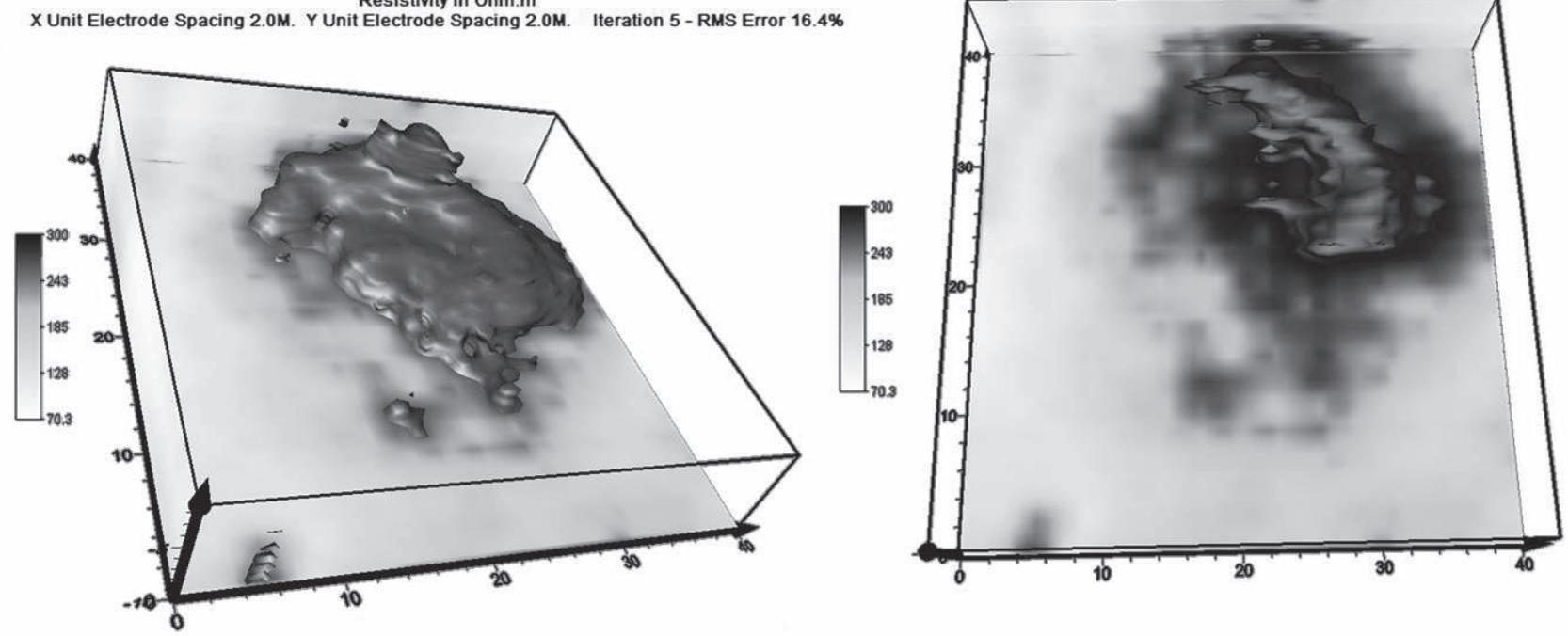

Figure 3. Pogorelka survey result: 3D DC tomography (top), NEMFIS 3D visualization (bottom).

Pazyryk culture, dated to 2500-3000 BC, can be found over a wide territory of the South Altay Mountains in Russia, Mongolia and China. This nomadic civilization belongs to the group of Mediterranean cultures and occupied territory in the Altay Mountains for merely a couple of centuries. They may have been refugees from Europe, escaping from the wars of Alexander the Great or some other unknown reason, and then went back to Europe.

Their burial mounds were kept safe because the wooden chambers were buried in permafrost. However, recently, due to global warming, some of these chambers have been unfrozen, leading to the decomposition of bodies, textiles and other buried organic material. Whether an ice lense is present inside a mound constitutes information of vital importance for deciding to excavate a mound or not. Dozens of similar mounds were explored using NEMFIS during
2005-2007. Estimation of the presence of ice in some of them helped to find some well preserved burial chambers and save resources for archaeologists.

The area of the town of Vengerovo, located about $400 \mathrm{~km}$ west of Novosibirsk, was populated by various nomadic civilizations between 3000 and 1000 BC. Remains of nomadic life can be found all over western Siberia in the form of mounds, buried settlements, burial and ceremonial objects etc. Almost all of them were robbed in the medieval age and especially in the 18th century by expeditions launched by Peter the Great, Emperor of Russia, to enrich his collection of ancient gold. Pogorelka is a typical example of a mound in the area. It was recently explored by NEMFIS and 3D DC tomography. IRIS Syscal Switch Pro instrument was used on a 2 by $2 \mathrm{~m}$ grid, 24 electrodes per line. The results of the study are shown in Fig. 3 which presents two maps 
of inverted resistivity distribution at depths $1-2.15 \mathrm{~m}$ and 2.15-3.47 $\mathrm{m}$. The maps were made using RES3D INV (Geotomo Software, Malaysia) software, Newton modified inversion. One observes the round form of the mound with anomalies of high resistivity. Following that, the NEMFIS sounding was performed using a 1 by $2 \mathrm{~m}$ grid. The $3 \mathrm{D}$ visualization as an isosurface of apparent resistivity of 240 $\mathrm{Ohm} \cdot \mathrm{m}$ (left) describes well the expected form of the inner mound structure. The $290 \mathrm{Ohm} \cdot \mathrm{m}$ isosurface (right) shows in detail the anomaly with its plan of half a horseshoe seen in the resistivity map.

\section{References}

Becker, H., Fassbinder, J. W. E., 1999. Magnetometry of a Scythian settlement in Siberia near Cicah in the Baraba steppe. Archaeological prospection 1999, Münich, 168-172.

Manstein, Y., Manstein, A., Santarato, G., 2003. Multifrequency electromagnetic sounding tool EMS. Prototype 3. Comparison with commercial devices. Abstracts book, EGU Conference 2003.

Manstein, A. K., Panin, G. L., Yu, S., 2008. Tikunov A device for shallow frequency-domain electromagnetic induction sounding. Russian Geology and Geophysics, 49: 430-436 